\title{
STABILITY LIMITATIONS ON HIGH-BETA TOKAMAKS
}

\section{MASTER}

BY

A. M, M. TODD, M, S, CHANCE

J. M. GREENE, R, C, GRIMM, J, L. JOHNSON AND

J. MANIKAM

\section{PLASMA PHYSICS LABORATORY}

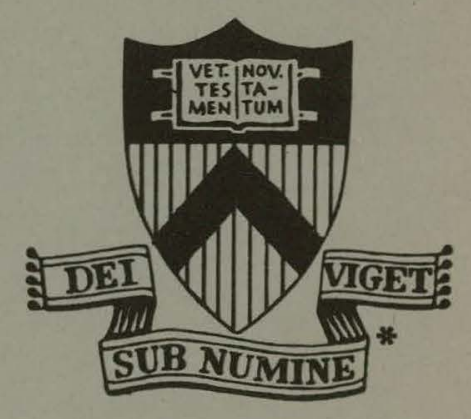

\section{PRINCETON \\ UNIVERSITY PRINCETON, NEW JERSEY}

This work was supported by U. S. Energy Research and Development Administration Contract E(11-1)-3073. Reproduction, translation, publication, use and disposal, in whole or in part, by or for the United States Government is permitted. 


\section{DISCLAIMER}

This report was prepared as an account of work sponsored by an agency of the United States Government. Neither the United States Government nor any agency Thereof, nor any of their employees, makes any warranty, express or implied, or assumes any legal liability or responsibility for the accuracy, completeness, or usefulness of any information, apparatus, product, or process disclosed, or represents that its use would not infringe privately owned rights. Reference herein to any specific commercial product, process, or service by trade name, trademark, manufacturer, or otherwise does not necessarily constitute or imply its endorsement, recommendation, or favoring by the United States Government or any agency thereof. The views and opinions of authors expressed herein do not necessarily state or reflect those of the United States Government or any agency thereof. 


\section{DISCLAIMER}

Portions of this document may be illegible in electronic image products. Images are produced from the best available original document. 
NOTICE

This report was prepared as an account of work sponsored by the United States Government. Neither the United States nor the United States Energy Research and Development Administration, nor any of their employees, nor any of their contractors, subcontractors, or their employees, makes any warranty, express or implied, or assumes any legal liability or responsibility for the accuracy, completeness or usefulness of any information, apparatus, product or process disclosed, or represents that its use would not infringe privately owned rights.

Printed in the United States of America.

Available from

National Technical Information Service

U. S. Department of Commerce 5285 Port Royal Road

Springfield, Virginia 22151

Price: Printed Copy $\$ \ldots$; Microfiche $\$ 3.00$

NTIS

*Pages

$1-50$

$51-150$

$151-325$

326-500

501-1000
Selling Price

$\$ 4.00$

5.45

7.60

10.60

13.60 
Stability Limitations on High-Beta Tokamaks

A. M. M. Todd, M. S. Chance, J. M. Greene, R. C. Grimm, $\mathrm{J}$. L. Johnson, and J. Manickam

Plasma Physics Laboratory, Princeton University Princeton, New Jersey 08540

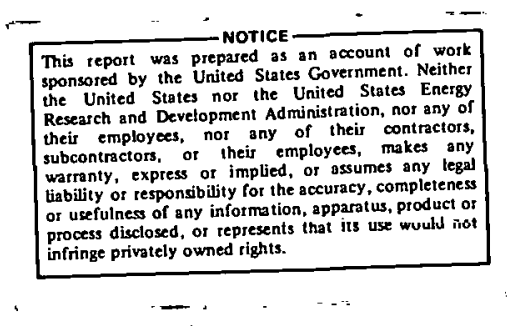


Stability Limitations on High-Beta Tokamaks*

A. M. M. Todd, M. S. Chance, J. M. Greene, R. C. Grimm, J. L. Johnson ${ }^{\dagger}$, and J. Manickàm

Plasma Physics Laboratory, Princeton University Princeton, New Jersey 08540

\begin{abstract}
The MHD equilibrium and stability limitations on the maximum pressure achievable by means of the flux-conserving tokamak concept are investigated. Stability criteria associated with ballooning effects appear to provide the most stringent limitation.
\end{abstract}


The flux-conserving tokamak concept ${ }^{1}$ has provided a prescription for choosing achievable plasma parameters when rapidly heating a plasma from an easily formed low-pressure configuration. It has been shown that equilibrium considerations do not provide an absolute limit to the maximum pressure that can be contained. MHD stability considerations can provide such a limit. We study this problem numerically, using the PEST parkage, ${ }^{2}$ by treating a geries of equilibria that could be associated with the TFTR device ${ }^{3}$ being built at the Princeton University Plasma Physics Laboratory.

We choose as our starting point the equilibrium of Fiq, 1 . The pressure is proportional to $\left(\Psi_{b}-\Psi\right)^{2}$ with $\Psi_{b}$ the poloidal flux at the plasma boundary.. The safety factor $q \equiv d \Phi / d \Psi$, with $\Phi$ the toroidal flux, increases from 1.04 at the axis to 3.77 at the boundary. The plasma, with aspect ratio $R / a=4.6$ where $R$ is the distance from the major axis to the magnetic axis and $\pi^{2}$ the cross-sectional area of the plasma surface, is supported by currents in external poloidal field coils that create a favorable field index throughout the plasma. The: fusion-power averaged pressure is

$$
\beta^{*} \doteq 2 \mu_{0}\left(\int \mathrm{p}^{2} \mathrm{dV} / \mathrm{V}\right)^{1 / 2} / \mathrm{B}_{0}^{2}=1.68
$$

for this configuration. Other commonly used pressure averages include $\vec{B} \equiv 2 \mu \int \mathrm{pdV} / \mathrm{B}_{\mathrm{o}}^{2} \mathrm{~V}=1.0 \%$ and $\beta_{\mathrm{p}} \equiv 4 \int \mathrm{pdV} / \int\left(I^{\prime} \mathrm{V} / \mathrm{N}^{\prime}\right) \mathrm{d} \Psi=$ $2.1 \%$ with. I the toroidal current, $\mathrm{V}$ the volume, and $\mathrm{B}_{\mathrm{O}}$ 
the toroidai field: The difference between $\beta^{*} \ldots$ and $\bar{\beta}$ depends strongly on the shape of the pressure distribution.

We consider the effect on this equilibrium of increasing the material pressure, keeping the shape of the pressure distribution, the magnetic fluxes, and the position of the magnetic axis fixed. To prevent the outward shift associated with a pressure increase, we raise the current in the poloidal field coils, maintaining the shape of the field. The series of equilibria is summarized in Fig. 2. The aspect ratio decreases slightly since the plasma must expand to maintain the toroidal flux. The poloidal beta tends to saturate near the aspect ratio. As shown in Fig. 3, a plot of the flux surfaces when $B^{*}=6.08$, the separatrix in the vacuum region approaches the plasma as the pressure is increased. As it comes close, the change in shape of the magnetic surfaces modifies their inductance and thus induces a large current in the plasma close to the surface. Our numerical scheme breaks down when the separatrix gets too close to the surface.

We now consider the stability problem. Evaluation of the usual localized instability criteria ${ }^{4}$ shows that both ideal and resistive interchange modes should be stable. We investigate nonlocal instaḅilities using a Galerkin method ${ }^{2}$ to find the eigenmones $\xi_{2}$. We use finite elements in the $\Psi_{-}$ direction, Fourier-analyze in the poloidal and toroidal angles $\theta$ and $\phi, \xi=\sum_{m, \ell} \xi_{m, \ell, n} \Phi_{m}(\Psi) \exp i(\ell \theta-n \phi)$, and treat the different $n$-modes separately. 
The axisymmetric modes with $\mathrm{n}=0$ are stable. This should be expected since the shape of the externally imposed field was tailored carefully to avoid such instabilities. Instabilities with $n=1$ set in for $\beta^{*}>1.98$ as shown in Fig. 4. The growth rate is normalized to the poloidal Alfvén time. The projection of the displacement vector onto a constant $\phi$ plane is shown in Fig. 5. The $\ell=1$ component dominates at. the axis; higher $l$ 's emerge near the rational surfaces where, their perturbed fields are small, i.e.., where $|\ell-\mathrm{nq}|<1$, and thus the $\ell=4$ mode is largest at the surface. The modes twist with the field lines in going around the torus with largest amplitude on the outside. The system is found to be stable to this mode when the plasma surface is held fixed. Over all, this mode has the character of an $\mathcal{\ell}=4 \mathrm{kink}$ with an enhanced and deepened vortex on the outer side of the plasma column.

Higher-n modes set in for somewhat large $\beta^{*}$ 's as shown for $\mathrm{n}=3$ in Fig. 4. Holding the plasma boundary fixed decreases the growth rate but does not eliminate the instability. A typical dispiacement vector is shown in Fig. 6. The instability assumes' the form of vortices which are much stronger on the outside of the plasma column. This can be seen clearly in Fig. 7, where the normal component of $\xi$ is plotted as a function of $\theta$ for several surfaces. The apparent decrease in growth rate as $\beta^{*}$ is increased in the fixed-surface $n=3$ case in Fig. 4 'is due to the difficulty in representing 
the increasing localization of the perturbation with a finite set of expansion functions.

To understand the importance of these modes, it is useful to consider the potential energy associated with small distortions from equilibrium ${ }^{2}$

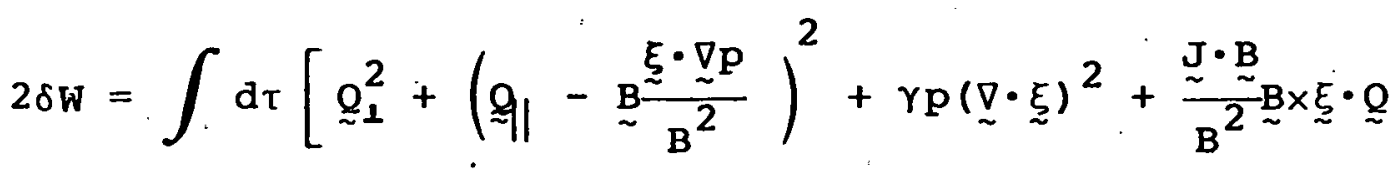

$$
\begin{aligned}
& -2 \xi \underset{\sim}{\nabla} \cdot \underset{\sim}{\nabla} \quad \underset{\sim}{\xi} \cdot \underset{\sim}{k}]
\end{aligned}
$$

with $\underset{\sim}{\mathbb{Q}} \equiv \underset{\sim}{\nabla} \times(\underset{\sim}{\xi} \times \underset{\sim}{\text { B }})$ the perturbed field and $\underset{\sim}{\kappa}$ the field-line curvature. The first term in Eq. (2) is stabilizing. The unstable modes have $\underset{\sim}{\nabla} \cdot \underline{\sim}_{\perp}=-2 \underset{\sim}{\underline{k}} \cdot \underset{\sim}{k}$ to eliminate the second term and $\xi_{\|_{5}}$ picked to make $\underset{\sim}{\nabla} \cdot \underset{\sim}{\xi}=0$, thereby removing the third term. Kink modes ${ }^{5}$ are driven primarily by the interaction of the perturbed field with the force-free part of the current, the fourth term. The toroidal field provides a large curvature of order $1 / R$, unfavorable on the outside of the plasma, and favorable on the inside, such that the average over the surface is stabilizing. Then interchange modes ${ }^{6}$ with $\underset{\sim}{\xi}$ constant along field lines are stable. Relaxing this constraint on $\underset{\xi}{\xi}$ allows the unfavorable curvature to drive the modes unstable despite the increase in

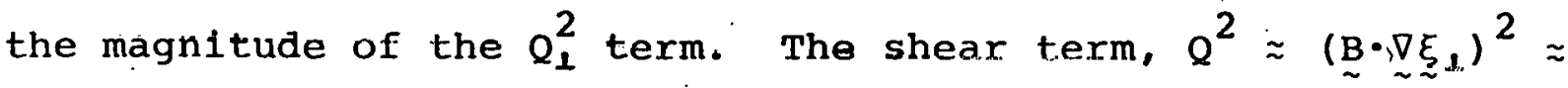
$(B / q R)^{2} \xi^{2}$ with $q R$ the connection length, and the curvature term, $2 \underset{\sim}{\xi} \cdot \underset{\sim}{p} \underset{\sim}{\xi} \cdot \underset{\sim}{k} \approx 2(p / a) \xi^{2} / R$, balance when $B^{*} \leqslant a / q^{2} R \approx 1.58$ for our parameterg. These ballnoning effects augment the driving forces for kink modes to establish an upper limit on $\beta^{*} .^{7}$ 
The ballooning; modes, illustrated by the fixed-wall $\mathrm{n}=3$ case, provide a mechanism for moving plasma from the center to the outer surface. Since they cannot be cured by tailoring the current distribution, ${ }^{8}$ these modes pose a severe limitation on the achievable beta. They appear to be described by a quasimode formulation. ${ }^{9}$. Thus it is reasonable to expect that the instability will develop non-linearly on a resistive instability time scale.

The low $\beta^{*}$ 's found here are due to the large values of the aspect ratio and safety factor, chosen to ensure stability with respect to axisymmetric and kink modes. With careful design it should be possible to increase this limit significantly. Clearly a better understanding of these instabilities is essential.

We appreciate the interest shown by H. P. Furth and P. H. Rutherford. 


\section{REFERENCES}

* This work was supported by the U.S. Energy Research and Development Agency Contract E(11-1)-3073 with Princeton University.

† On loan from westinghouse Research Laboratories.

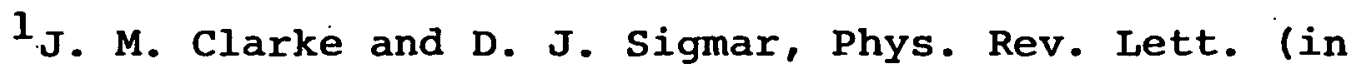
press).

${ }^{2}$ R. C. Grimm, J. M. Greene, and J. L. Johnson, in Meth- :ods in Computational Physics (Academic Press, N, Y., 1976) Vol. 16, p. 253.

${ }^{3}$ Tokamak Fusion Test Reactor Final Conceptual Design Report, Princeton University Plasma Physics Laboratory and Westinghouse Electric Corporation Fusion Power systems Department Report No. PPPL - 1275, PH, R - 001, Feb., 1976.

${ }^{4}$ A. H. Glasser, J. M. Greene, and J. L. Johnson, Phys. Fluids 18, 875 (1975).

5. D. Kruskal, J. L. Johnson, M. B. Gottlieb, and L. M. Goldman, Phys. Fluids 1,421 (1958).

${ }^{6}$ J. M. Greene and J. L. Johnson, Plasma Physics 10, 729 (1968).

7J. P. Freidberg, J. P. Goedbloed, W. Grossmann, and F. A. Haas, in Plasma Physics and 'Controlled Nuclear Fusion Research 1974, (İ.A.E.A., Vienna, 1975) Vol. 1, p. 505.

${ }^{8}$ A. M. Glasser, H. P. Furth, and P. H. Rutherford, Phys. Rev. Lett. (in press).

${ }^{9}$ K. V. Roberts and J. B. Taylor, Phys. Fluids 8,315 (1965). 


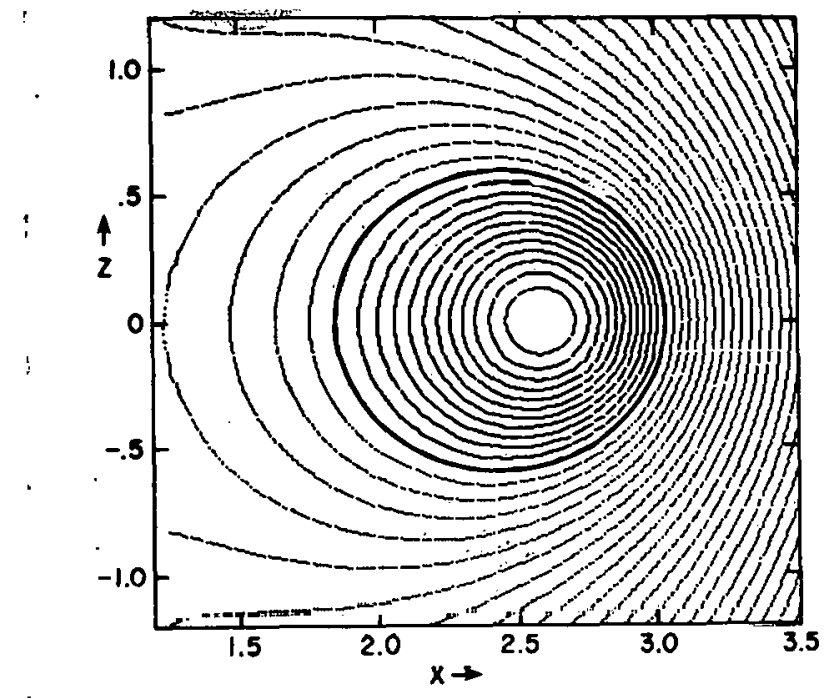

771026

Fig. 1. Flux surfaces for a TFTR configuration with $\beta^{\text {* }}$ $=1.6 \%$. The heavy solid curve is the plasma surface.

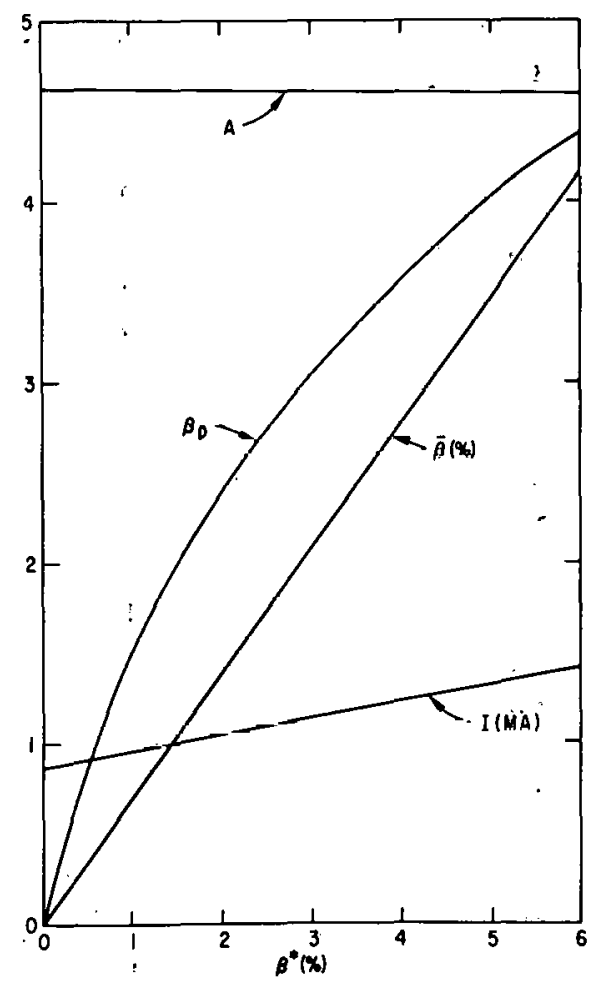

Fig. 2. Properties of the flux-conserved equilibria. 
()

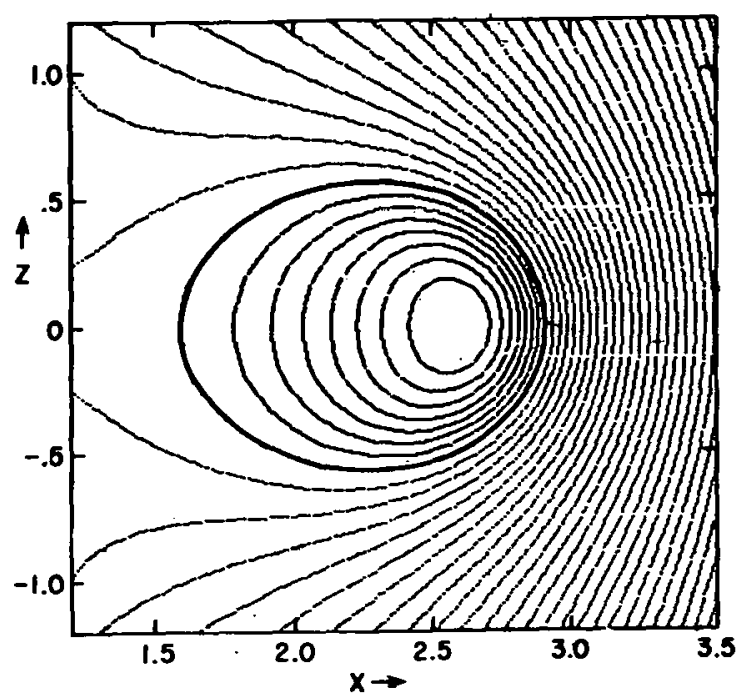

774027

Fig. 3. Flux surfaces with $B^{*}=6.0 \%$

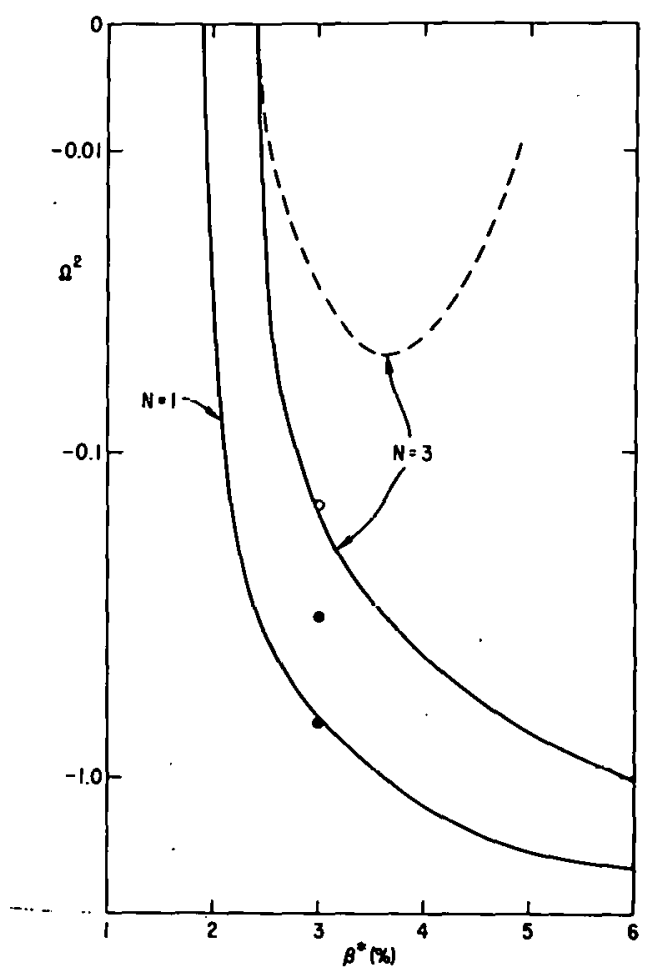

Fig. 4. Instability growth rates on a sinh. $100 \Omega^{2}$
for $n=1$ and $n=3$ modes with a free boundary (solid scale for $n=1$ and $n=3$ modes with a free boundary (solid curves) and for $n=3$ modes with a fixed boundary (dashed curve). The fixed-boundary $n=1$ mode is stable. These calculations used twelve finite elements in $\psi$ and twenty-one Fourier components in $\theta$. Extrapolation from converqence studies results in the values shown by the dots. 


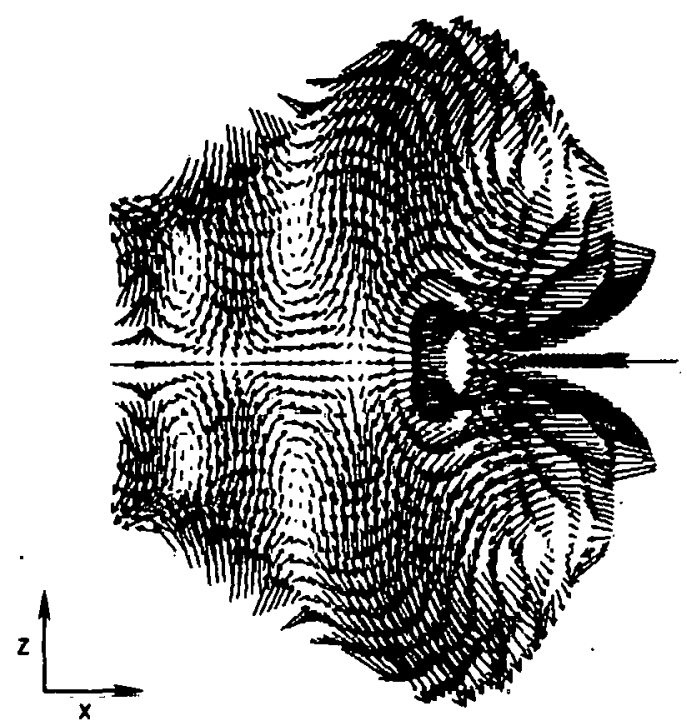

774025

Fig. 5. Projection of the displacement vector for the free-boundary $\mathrm{n}=1$ mode at $B^{\star}=. . \cap$ ?

\section{4}

Fig. 6. Displacement vector for the fixed-boundary $n=3$ mode at $B^{\star}=3.0 \%$.

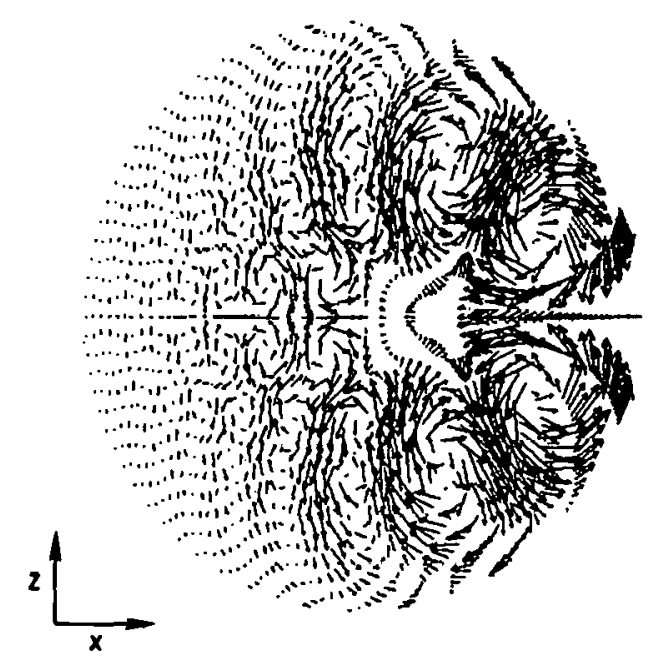




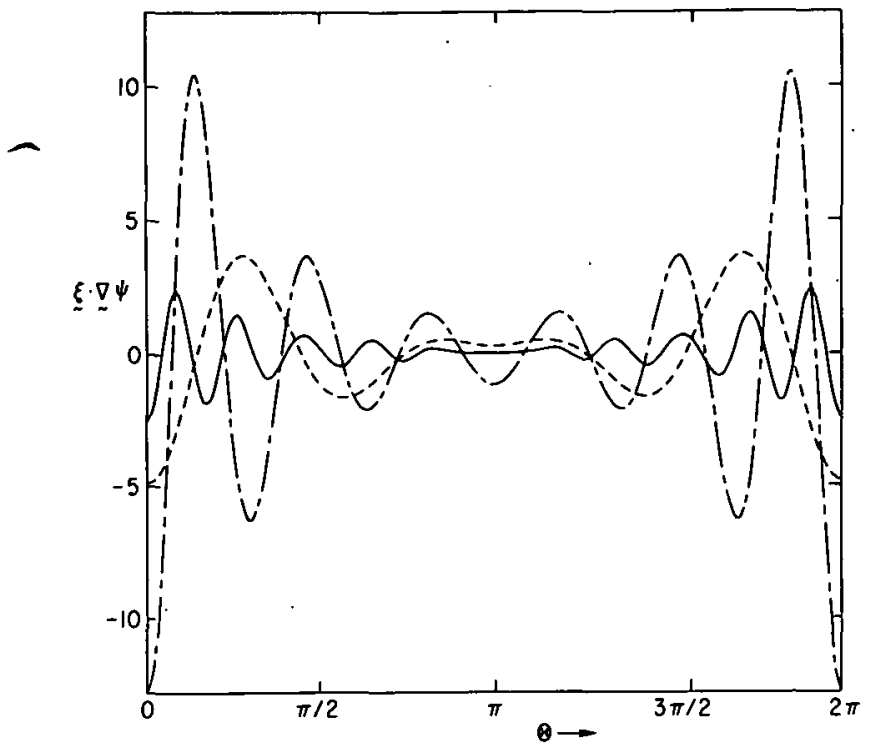

774030

Fig. 7. The normal component of $\underset{\sim}{\xi}$ as a function of the poloidal angle on surfaces with $\psi / \psi_{b}=1 / 12$ (dashed curve), $\psi_{\mathrm{b}}=1 / 2$, (broken curve), and $\psi / \psi_{\mathrm{b}}=11 / 12$ (solid curve) at $B^{*}=3.0 \%$. 